\title{
Infection with SARS-CoV-2 causes abnormal laboratory results of multiple organs in patients
}

\author{
Ai-Ping Yang ${ }^{1}$, Hui-Ming Li $^{2}$, Wen-Qiang Tao ${ }^{3}$, Xue-Jing Yang ${ }^{4}$, Min Wang ${ }^{1}$, Wen-Juan Yang ${ }^{1}$, Jian- \\ Ping Liu² \\ ${ }^{1}$ Department of Clinical Laboratory, Zhejiang Xiaoshan Hospital, Hangzhou, Zhejiang Province, China \\ ${ }^{2}$ Department of Clinical Laboratory, The First Affiliated Hospital of Nanchang University, Nanchang, Jiangxi, China \\ ${ }^{3}$ Department of Critical Care Medicine, The First Affiliated Hospital of Nanchang University, Nanchang, Jiangxi, \\ China \\ ${ }^{4}$ Department of Clinical Laboratory, The First Affiliated Hospital of Zhejiang Chinese Medical University, Hangzhou, \\ Zhejiang Province, China
}

Correspondence to: Jian-Ping Liu; email: 16915526@qq.com

Keywords: coronavirus, COVID-19, lymphopenia, inflammatory cytokine, D-dimer

Received: March 19, $2020 \quad$ Accepted: April 25, $2020 \quad$ Published: June 1, 2020

Copyright: Yang et al. This is an open-access article distributed under the terms of the Creative Commons Attribution License (CC BY 3.0), which permits unrestricted use, distribution, and reproduction in any medium, provided the original author and source are credited.

\section{ABSTRACT}

Aim: To evaluate the clinical value of abnormal laboratory results of multiple organs in patients with coronavirus disease 2019 (COVID-2019) and to help clinicians perform correct treatment.

Results: Elevated neutrophil-to-LYM ratio (NLR), D-dimer(D-D), interleukin (IL)-6, IL-10, IL-2, interferon-Y, and age were significantly associated with the severity of illness. However, significant and sustained decreases were observed in the LYM subset $(p<0.05)$. D-D, T cell counts, and cytokine levels in severe COVID-19 patients who survived the disease gradually recovered at later time points to levels that were comparable to those of mild cases. Second, D-D increased from 0.5 to 8 , and the risk ratio increased from 2.75 to 55, eventually leading to disseminated intravascular coagulation. Moreover, the acute renal function damage occurred earlier than abnormal heart and liver functions $(p<0.05)$.

Conclusions: The degrees of lymphopenia and proinflammatory cytokine storm were higher in severe COVID-19 patients than in mild cases. The degree was associated with the disease severity. Advanced age, NLR, D-D, and cytokine levels may serve as useful prognostic factors for the early identification of severe COVID-19 cases.

Methods: Peripheral blood samples were collected from 93 confirmed COVID-19 patients. The samples were examined for lymphocyte (LYM) subsets by flow cytometry and cytokine profiles by specific immunoassays. The receiver operating characteristic curve was applied to determine the best diagnostic thresholds for laboratory results, and principal component analysis was used to screen the major risk factors. The prognostic values were assessed using the Kaplan-Meier curve and univariate and multivariate COX regression models.

\section{INTRODUCTION}

Coronavirus is a large virus family known to cause multiple system infections in various animals and mainly respiratory tract infections, such as severe acute respiratory syndrome (SARS) [1-3] and the
Middle East respiratory syndrome (MERS) [4], in humans. Although the clinical characteristics of coronavirus disease 2019 (COVID-19) have been broadly defined [5], an outline of the most representative laboratory abnormalities observed in patients with COVID-2019 is still incomplete [6-7]. 
Laboratory medicine plays an essential role in the early detection, diagnosis, and management of numerous diseases [8]. COVID-2019 is no exception to this rule. Nevertheless, the role of laboratory diagnostics extends beyond etiological diagnosis and epidemiologic surveillance, whereby in vitro diagnostic tests are commonly used for assessing disease severity, defining the prognosis, patient follow-ups, treatment guide, and therapeutic monitoring [9]. Diagnostics identify the defining laboratory results and clinical characteristics with high precision and unravel the risk factors associated with mortality.

Lymphopenia and inflammatory cytokine storm are typical laboratory abnormalities observed during highly pathogenic coronavirus infections, such as SARS coronavirus (SARS-CoV) and MERS coronavirus (MERS-CoV) infections; these abnormalities are believed to be associated with disease severities [10]. Severe inflammatory responses contribute to the weakening of the adaptive immune response, which results in an imbalanced immune response and COVID-19. Therefore, circulating biomarkers that can represent the status of inflammation and immunity are recognized as potential predictors for the prognosis of COVID-19 patients [11]. Recent studies have also reported decreases in the lymphocyte (LYM) counts in the peripheral blood and increases in serum inflammatory cytokine levels in COVID-19 patients [12]. However, how different LYM subsets and the kinetics of inflammatory cytokines change in the peripheral blood in COVID-19 remain unclear. In this study, the changes in LYM subsets and cytokines profiles in the peripheral blood of COVID-19 patients with distinct disease severities were longitudinally characterized.

\section{RESULTS}

\section{Results of white blood cell (WBC) count, LYM subset, and demographics of the study subjects}

Table 1 showed the demographics and clinical characteristics of the study subjects. The proportion of randomly selected severe cases, including critical illness, was $25.8 \%$. The average age of those was 58 years old, as well as 42 years old of non-severe patients. The age and WBC count, NLR, LYM-monocyte (MON) ratio, platelet-to-LYM ratio, CRP, d-NLR, and D-dimer (D-D) of severe ill patients were significantly higher than those of non-severe patients $(\mathrm{p}<0.01)$. By contrast, the results of $\mathrm{CD} 3+, \mathrm{CD} 3+\mathrm{CD} 4+, \mathrm{CD} 3+\mathrm{CD} 8+, \mathrm{CD} 56+\mathrm{CD} 16+$, and CD3-CD19+ were notably low $(\mathrm{p}<0.01)$. However, no significant difference was observed in terms of gender, Fib, albumin-to-fibrin ratio, and CD4+/CD8+ ( $>$ >0.05).

\section{Results of clinical characteristics of the study subjects}

All patients had no contact with wild animals. However, 27.8\% (26/93) of the patients recently traveled to Wuhan, and $73.1 \%$ (68/93) of those had contact with people from Wuhan. Fever and cough were the first and most common symptoms before admission. A total of $50(53.7 \%)$ patients in both groups had co-morbidities, including diabetes $(22.5 \%$; 21/93), hypertension $(24.7 \%$; 23/93), hepatitis B (11.8\%; 11/93), abnormal liver function (13.9\%; $13 / 93)$, heart disease $(13.9 \% ; 13 / 93)$, and renal dysfunction $(10.7 \%$; 10/93) (Table 2). A total of $70.8 \%$ of severe case patients and $79.7 \%$ of mild case patients had fever. Meanwhile, no significant difference was observed in the degrees of temperature $(\mathrm{p}=0.37)$, fatigue $(\mathrm{p}=0.213)$, cough $(\mathrm{p}=0.496)$, pharyngalgia $\quad(\mathrm{p}=0.748)$, dizziness $\quad(\mathrm{p}=0.109)$, headache $(\mathrm{p}=0.831)$, chest pain $(\mathrm{p}=0.456)$, vomiting $(\mathrm{p}=0.762)$, diarrhea $(\mathrm{p}=0.999)$, heart disease $(\mathrm{p}=0.663)$, and abnormal liver function $(\mathrm{p}=0.659)$ between the two groups (Table 2). The severe case patients showed significantly high frequencies in the occurrence of diabetes $(\mathrm{p}<0.01)$, hypertension $(\mathrm{p}<0.01)$, renal dysfunction $(\mathrm{p}<0.05)$, chill $(\mathrm{p}<0.05)$, shivering $(\mathrm{p}<0.05)$, sputum production $(\mathrm{p}<0.01)$, and nausea $(\mathrm{p}<0.01)($ Table 2$)$.

\section{Analysis of inflammatory cytokine levels in the serum of COVID-19 patients}

A previous study demonstrated the changes in the levels of inflammatory cytokines, such as IL-2, IL-7, IL-10, and tumor necrosis factor (TNF)- $\alpha$, in the serum of COVID-19 patients [4]. Therefore, the changes in inflammatory cytokine levels, including IL-2 and IL-12P70, were further characterized in the serum of our patient cohort. The severe case patients showed significantly high levels of IL-2 $(\mathrm{p}<0.05)$, IL$6(\mathrm{p}<0.01)$, IL-8 $(\mathrm{p}<0.05)$, and IL-10 $(\mathrm{p}<0.01)$ (Table 3 ). No significant difference was observed in the degrees of IL-5, IFN- $\alpha$, IL- $1 \beta$, IFN- $\gamma$, IL-17, IL-4, and IL-12P70 between the two study groups (Table 3 ). The laboratory reference values for each cytokine are as follows: IL $5 \leq 3.1 \mathrm{pg} / \mathrm{mL}$, IFN- $\alpha \leq 8.5 \mathrm{pg} / \mathrm{mL}$, IL-2 $\leq 7.5 \mathrm{pg} / \mathrm{mL}, \mathrm{IL}-6 \leq 5.4 \mathrm{pg} / \mathrm{mL}, \mathrm{IL}-1 \beta \leq 12.4 \mathrm{pg} / \mathrm{mL}$, IL-10 $\leq 12.9 \mathrm{pg} / \mathrm{mL}$, IFN- $\gamma \leq 23.1 \mathrm{pg} / \mathrm{mL}$, IL- $8 \leq 5.6$ $\mathrm{pg} / \mathrm{mL}$, IL- $17 \leq 21.4 \mathrm{pg} / \mathrm{mL}, \mathrm{IL}-4 \leq 8.56 \mathrm{pg} / \mathrm{mL}$, and $\mathrm{IL}-12 \mathrm{P} 70 \leq 3.4 \mathrm{pg} / \mathrm{mL}$.

\section{Acute heart, liver, and kidney function damage in severe COVID-19 patients}

Among the 24 severe COVID-19 patients, only 16 cases were selected because of their complete electronic 
Table 1. Results of WBC count, lymphocyte subset and demographic in the study subjects.

\begin{tabular}{|c|c|c|c|c|}
\hline Laboratory results & Total & non-sever $(n=69)$ & $\begin{array}{l}\text { Severe (including critical illness) } \\
(n=24)\end{array}$ & P-value \\
\hline $\operatorname{age}(\mathrm{M} \pm \mathrm{SD})$ & $46.4 \pm 17.6$ & $42.1 \pm 18.6$ & $57.9 \pm 11.8$ & $<0.05$ \\
\hline $\operatorname{sex} \pm \mathrm{M} / \mathrm{F} \pm$ & $56 / 37$ & $38 / 31$ & $18 / 6$ & 0.135 \\
\hline $\mathrm{WBC}(\mathrm{M} \pm \mathrm{SD})$ & $6.9 \pm 3.9$ & $6.4 \pm 2.4$ & $9.1 \pm 5.6$ & $<0.01$ \\
\hline LYM & $1.04 \pm 0.64$ & $1.17 \pm 0.63$ & $0.65 \pm 0.54$ & $<0.01$ \\
\hline NEU & $5.38 \pm 3.6$ & $4.55 \pm 0.21$ & $7.73 \pm 5.4$ & $<0.01$ \\
\hline MON & $0.43 \pm 0.46$ & $0.41 \pm 0.2$ & $0.5 \pm 0.84$ & $<0.05$ \\
\hline $\mathrm{NLR}(\mathrm{M} \pm \mathrm{SD})$ & $10.8 \pm 15.6$ & $4.8 \pm 3.5$ & $20.7 \pm 24.1$ & $<0.01$ \\
\hline $\mathrm{d}-\mathrm{NLR}(\mathrm{M} \pm \mathrm{SD})$ & $5.07 \pm 5.5$ & $3.3 \pm 1.9$ & $9.8 \pm 7.8$ & $<0.01$ \\
\hline $\mathrm{LMR}(\mathrm{M} \pm \mathrm{SD})$ & $3.42 \pm 4.6$ & $4.1 \pm 6.0$ & $2.1 \pm 1.6$ & $<0.01$ \\
\hline $\mathrm{PLR}(\mathrm{M} \pm \mathrm{SD})$ & $255.8 \pm 226.1$ & $176.7 \pm 84.2$ & $436.5 \pm 329.2$ & $<0.01$ \\
\hline $\mathrm{CRP}(\mathrm{M} \pm \mathrm{SD})$ & $33.8 \pm 48.4$ & $20.1 \pm 24.5$ & $53.9 \pm 60.1$ & $<0.01$ \\
\hline CD3+ & $629.4 \pm 489.4$ & $763.8 \pm 483.3$ & $222.2 \pm 195.2$ & $<0.01$ \\
\hline $\mathrm{CD} 3+\mathrm{CD} 4+$ & $370.6 \pm 264.3$ & $448.7 \pm 254.9$ & $132.6 \pm 98.5$ & $<0.01$ \\
\hline $\mathrm{CD} 3+\mathrm{CD} 8+$ & $219.8 \pm 209.3$ & $264.6 \pm 217.4$ & $83.9 \pm 97.2$ & $<0.01$ \\
\hline CD4+/CD8+ & $2.06 \pm 0.97$ & $2.01 \pm 0.98$ & $2.0 \pm 0.97$ & 0.754 \\
\hline CD56+CD16+ & $148.7 \pm 132.3$ & $169.3 \pm 141.3$ & $85.9 \pm 76.7$ & $<0.01$ \\
\hline CD3-CD19+ & $124.8 \pm 103.9$ & $141.3 \pm 111.2$ & $75.2 \pm 53.7$ & $<0.01$ \\
\hline D-dimer & $3.2 \pm 8.1$ & $0.54 \pm 0.42$ & $16.6 \pm 23.1$ & $<0.01$ \\
\hline Alb & $38.6 \pm 6.9$ & $41.4 \pm 5.8$ & $31.9 \pm 4.4$ & $<0.05$ \\
\hline Fib & $3.6 \pm 1.3$ & $3.8 \pm 1.2$ & $3.2 \pm 1.4$ & 0.179 \\
\hline AFR & $12.2 \pm 5.7$ & $12.2 \pm 5.1$ & $12.5 \pm 7.4$ & 0.585 \\
\hline
\end{tabular}

Albumin(Alb), Fibrin(Fib), Albumin-to-Fibrin (AFR), white blood count cell(WBC), neutrophil-to-lymphocyte ratio (NLR), derived neutrophil-to-lymphocyte ratio (d-NLR) (neutrophil count divided by the result of white cell count minus neutrophil count), platelet-to-lymphocyte ratio (PLR) and lymphocyte-to-monocyte ratio (LMR), C-reactive protein(CRP), lymphocyte (LYM), Neutrophils (NEU), Monocyte (MON).

medical records, subsequently, the abnormal laboratory results of multiple organs, such as kidney (creatinine and urea), liver (alanine aminotransferase and aspartate aminotransferase), and heart (High sensitivity troponin $\mathrm{T}$ and creatine kinase-MB), were further analyzed. The laboratory results of acute renal function injury $(4.94 \pm 1.69)$ occurred earlier than those of liver $(7.81 \pm 1.86)$ and heart functions $(6.19 \pm 1.83)$. One-way analysis of variance showed a statistically significant difference in laboratory results $(\mathrm{p}<0.01)$ between kidney and heart $(\mathrm{p}=0.056)$, kidney and liver $(\mathrm{P}<0.01)$, and heart and liver functions $(\mathrm{P}=0.014)$. However, several patients presented opposite trends. Further checking of the electronic medical record revealed that these patients were infected with hepatitis B and other common diseases, such as liver fibrosis, cyst, fatty liver, and cirrhosis (Figure 1).

\section{Prognostic factors for the identification of severe COVID-19 cases}

PCA was performed by SPSS package "factor analysis" to identify correlated variables for distinguishing severe patients from mild case patients (Figure 2). The seven most contributing variables, namely, D-D, IL-6, IL-8, and NLR with a score of more than 2. CD3+, IL-10 and age with a score of more than 1 , which were selected as potential prognostic factors for further detailed statistical analysis. To assess the diagnostic value of the seven selected parameters, we calculated the ROC curve and area under the ROC curve (AUC) by SPSS package (Figure 3). The results of this analysis identified D-D with a higher AUC (0.958) than IL-6 (0.795), NLR (0.789), IL-8 (0.774), age (0.728), and IL-10 (0.717). With values of 49.5 for age, 3.3 for NLR, and 2.1 for D$\mathrm{D}$ dimer, CD3+could not be used as a potential 
Table 2. Baseline characteristics of patients infected with COVID-2019.

\begin{tabular}{lcccc}
\hline Baseline variables & Total(n=93) & non-sever (n=69) & $\begin{array}{c}\text { Severe (including critical } \\
\text { illness)(n=24) }\end{array}$ & P-Value \\
\hline Wuhan exposure(\%) & $29(31.1)$ & $21(30.4)$ & $9(37.5)$ & 0.524 \\
co morbidities (\%) & $50(53.7)$ & $29(42.1)$ & $21(87.5)$ & $<0.01$ \\
Diabetes & $21(22.5)$ & $8(11.6)$ & $13(54.2)$ & $<0.01$ \\
Hypertension & $23(24.7)$ & $7(10.1)$ & $16(66.8)$ & $<0.01$ \\
hepatitis B & $11(11.8)$ & $7(10.1)$ & $4(16.7)$ & 0.409 \\
Heart disease & $13(13.9)$ & $4(5.8)$ & $9(37.5)$ & $<0.01$ \\
Renal dysfunction & $10(10.7)$ & $2(2.9)$ & $8(33.3)$ & $<0.05$ \\
Abnormal liver & $13(13.9)$ & $9(13.0)$ & $4(16.7)$ & 0.659 \\
function & $55.4)$ & $3(4.3)$ & $2(8.3)$ & 0.456 \\
others & & & & 0.37 \\
Signs and symptoms & $72(77.4)$ & $55(79.7)$ & $17(70.8)$ & $<0.05$ \\
Fever & $22(23.6)$ & $12(17.4)$ & $10(41.6)$ & $<0.05$ \\
Chill & $11(11.8)$ & $5(7.2)$ & $6(25)$ & 0.213 \\
Shivering & $60(64.5)$ & $42(60.8)$ & $18(75)$ & 0.496 \\
Fatigue & $67(72.1)$ & $51(73.9)$ & $16(66.7)$ & $<0.01$ \\
Cough & $44(47.3)$ & $25(36.2)$ & $19(79.1)$ & 0.748 \\
Sputum production & $10(10.7)$ & $7(10.1)$ & $3(12.5)$ & 0.109 \\
Pharyngalgia & $17(18.3)$ & $10(14.5)$ & $7(29.1)$ & 0.831 \\
Dizziness & $18(19.3)$ & $13(18.8)$ & $5(20.8)$ & 0.051 \\
Headache & $28(30.1)$ & $17(24.6)$ & $11(45.8)$ & 0.456 \\
Chest tightness & $6(6.5)$ & $3(4.4)$ & $2(8.3)$ & 0.072 \\
Chest pain & $5(5.4)$ & $2(2.9)$ & $3(12.5)$ & $<0.01$ \\
Shortness of breath & $10(10.7)$ & $4(5.8)$ & $6(25)$ & 0.999 \\
Nausea & $1(1.1)$ & $1(1.5)$ & 0 & 0.762 \\
Diarrhoea & $3(4.3)$ & $2(2.9)$ & $1(4.2)$ & \\
Vomiting & & & \\
\hline
\end{tabular}

Table 3. Results of inflammatory cytokine levels in the serum of COVID-19 patients.

\begin{tabular}{lcccc}
\hline $\begin{array}{l}\text { Baseline } \\
\text { Variables }\end{array}$ & $\begin{array}{c}\text { Total (n=93) Mean } \\
\text { (Min-Max) }\end{array}$ & non-sever $(\mathbf{n = 6 9 )}$ & $\begin{array}{c}\text { Severe (including Critical } \\
\text { illness) }(\mathbf{n = 2 4})\end{array}$ & P-Value \\
\hline IL-5 & $2.39(0.2-40.3)$ & $1.99(0.2-10.4)$ & $2.95(0.24-40.3)$ & 0.438 \\
IFN-a & $2.31(0.84-22.5)$ & $2.03(0.96-4.83)$ & $2.69(0.84-22.5)$ & 0.617 \\
IL-2 & $2.21(0.74-25.4)$ & $1.74(0.74-4.76)$ & $2.88(1.23-25.36)$ & $<0.05$ \\
IL-6 & $26.5(0-1197.7)$ & $6.91(0-109.5)$ & $54.1(0-1197.7)$ & $<0.01$ \\
IL-1B & $14.6(0-121.5)$ & $14.1(0-49.7)$ & $15.5(0-121.5)$ & 0.398 \\
IL-10 & $3.27(0.96-39.5)$ & $2.81(0.08-10.2)$ & $4.81(1.15-39.5)$ & $<0.01$ \\
INF-Y & $6.32(0-150.9)$ & $4.46(0.08-67.1)$ & $8.96(0-150.9)$ & 0.218 \\
IL-8 & $108.3(0-3979.2)$ & $36.1(0-454.3)$ & $210.4(0.57-3979.2)$ & $<0.05$ \\
IL-17 & $1.67(0.17-10.6)$ & $1.56(0.17-10.3)$ & $1.84(0.79-10.6)$ & 0.399 \\
IL-4 & $1.47(0.53-7.14)$ & $1.51(0.53-7.14)$ & $1.42(0.61-3.56)$ & 0.804 \\
IL-12P70 & $0.93(0-4.87)$ & $0.85(0-4.5)$ & $1.04(0-4.87)$ & 0.44 \\
TNF-a & $19.8(0-1065)$ & $8.29(0-54.4)$ & $35.9(0-1065)$ & 0.577 \\
\hline
\end{tabular}


diagnostic biomarker for subsequent analysis with its AUC $<0.50$. Meanwhile, the results for IL-10 in severe case patients were statistically higher than those in nonsevere patients. However, the average results of both groups were within the reference range (IL-10 $\leq 12.9$ $\mathrm{pg} / \mathrm{mL}$ ). The further univariate analysis including five factors, such as IL-6, IL-8, D-D, age, and NLR, was used to calculate the odds ratios (ORs) between the severe and non-severe case groups. The results were obtained for NLR (OR: 4.6, 95\% Cl: 1.242-17.80), IL6 (OR: 6.625, 95\% Cl: 2.398-18.304), IL-8 (OR: 6.881, 95\% Cl: 2.453-19.298), and age (OR: 4, 95\% Cl: 1.493-10.714) with our patient cohort as predictive factors for severe COVID-19 (Table 4). D-D increased from 0.5 to 8 . The risk ratio between severe and nonsevere group increased from 2.75 to 55 and eventually leading to disseminated intravascular coagulation (DIC) $\left(\mathrm{y}=7.0651 \mathrm{x}-0.4251, \mathrm{R}^{2}=0.9893\right)$.

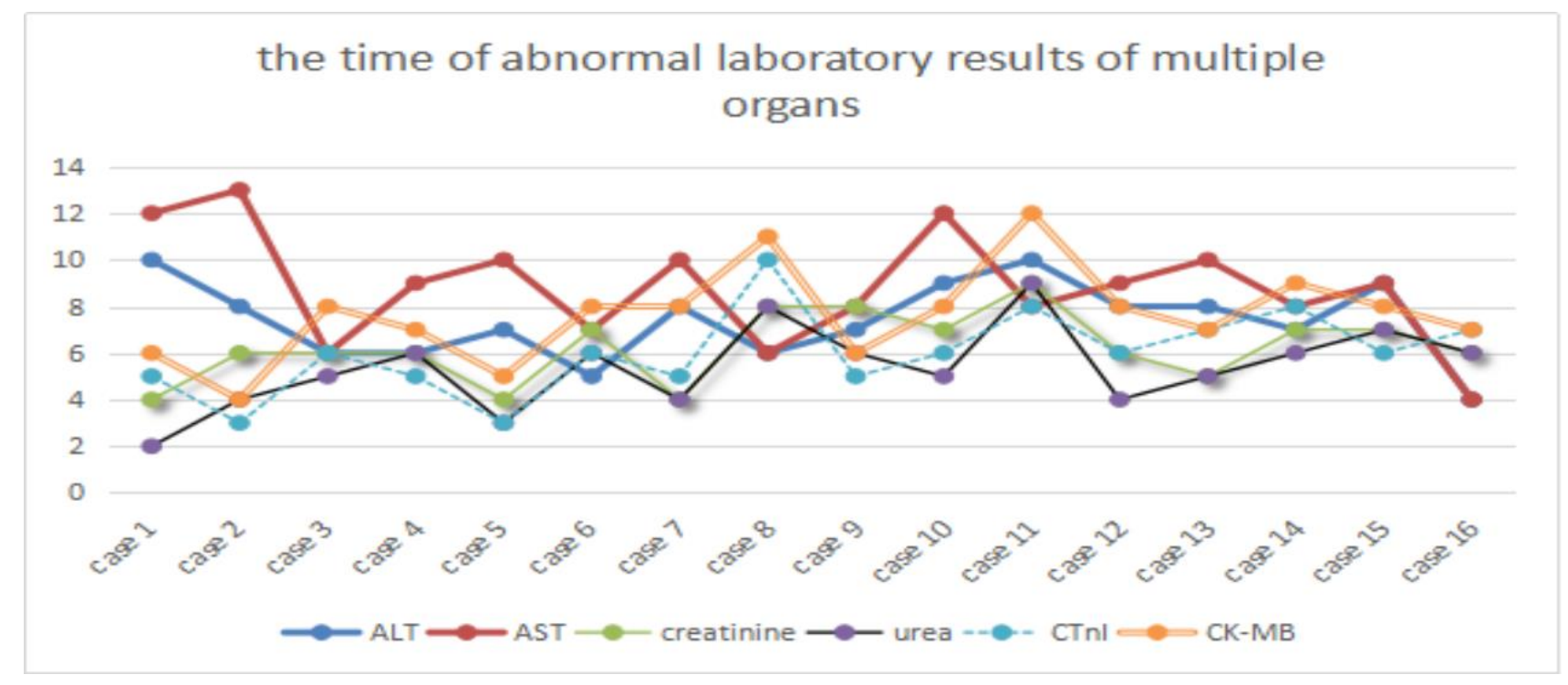

Figure 1. Time of abnormal laboratory results of multiple organs. ALT and AST, urea and creatinine, CTnI and CK-MB represent acute liver, renal and heart dysfunctions, respectively. X-axis represents the case number, whereas Y-axis denotes the time of abnormal laboratory results.

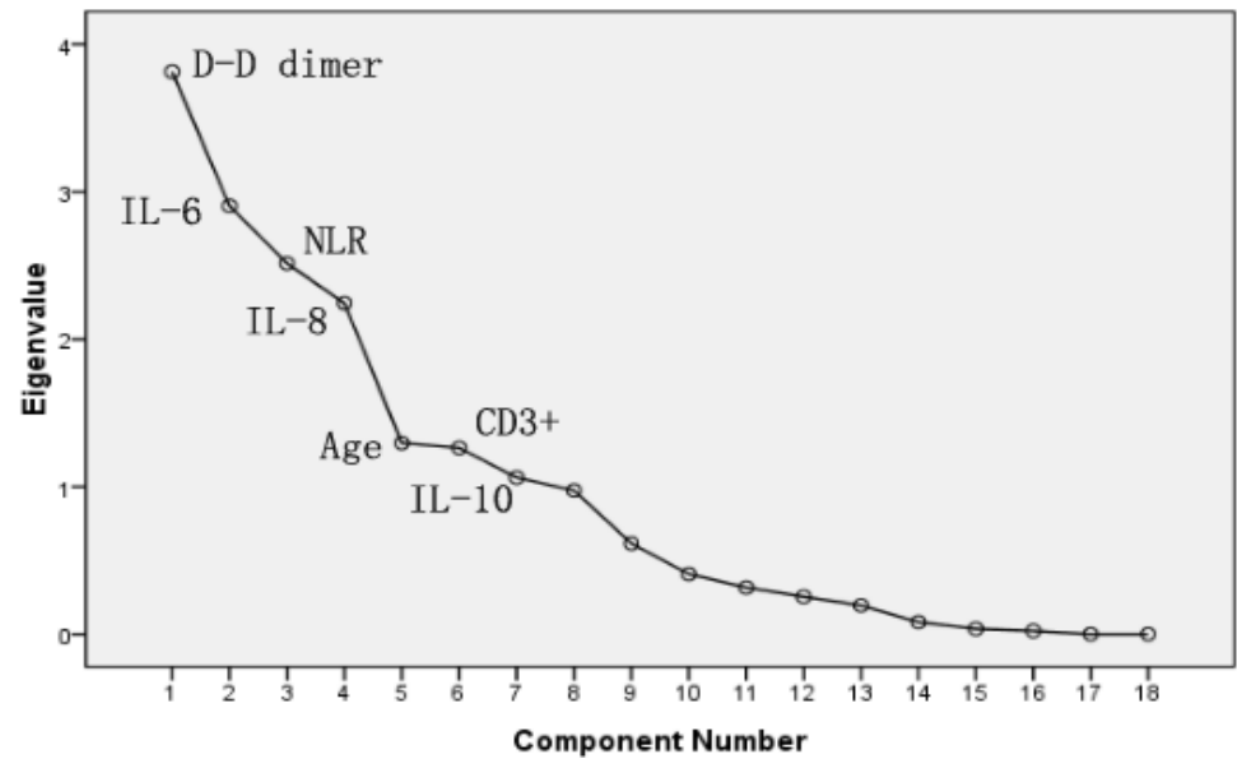

Figure 2. PCA Sreen point. 


\section{Kinetic analysis of WBC, NEU, LYM, MON, D-D dimer, and CRP in COVID-19 patients}

The absolute numbers of total WBCs (A), NEU (B), LYM (C), MON (D), CRP (E), and D-D (F) in the peripheral blood of mild (blue line) and severe (red line) COVID-19 patients were analyzed at different time points after hospital admission. Error bars represent mean \pm SD. From non-severe to severe cases, the time for D-D to change from lower normal limit to upper normal limit was significantly earlier than that for other biomarkers, and the change was more evident (Figure 4).

\section{DISCUSSION}

Since the outbreak of 2019-nCoV pneumonia in December 2019, the median incubation period was 4-7 days, and the fatality rate was relatively low [2]. By the end date of data collection (2020-02-29), less than 80,000 cases of COVID-19 were confirmed, and 2,835 patients died (CDC, China). The number of severe cases and deaths also increased every day [13]. In this study, severe case patients were older, and the proportion of underlying diseases was higher compared with mild case patients. Fever and cough were the first and most common symptoms before admission, whereas gastrointestinal symptoms, headache, shivering, pharyngalgia, and shortness of breath were rarely observed. This paper concluded the difference in viral tropism compared with SARS-CoV, MERS-CoV, and influenza $[14,15]$. Fever occurred in $43.8 \%$ of patients upon initial presentation and developed in $83.4 \%$ after hospitalization. Among COVID-19, SARS-CoV (1\%), and MERS-CoV (2\%) infections, the absence of fever is most frequent in COVID-19 cases [14, 16], and the patients may be missed if the surveillance case definition focuses heavily on fever detection [3]. Significantly high frequencies of severe cases were observed in elderly patients with diabetes or hypertension (Tables 1 and 2). The clinical characteristics of these patients were similar to those reported in previous studies. [2, 3, 17]. From non-severe to severe, the time for D-D to change from lower normal limit to upper normal limit was significantly earlier than that for other biomarkers (Figure 4). Therefore, the D-D should be monitored every other day, which should also be beneficial for patients.

After the discussion of the clinical features of COVID19 , we analyzed the immunological characteristics of peripheral blood in patients with COVID-19. Firstly, the LYM counts were normal in COVID-19 patients with mild diseases [18]. By contrast, almost all patients with severe diseases had lymphopenia, and the LYM counts in patients with a mortal outcome remained at a low level [19]. This study also confirmed the higher rates of developing lymphopenia in severe case patients than in mild case patients ( $99.6 \%$ vs $67.2 \%$ ). The development of lymphopenia in severe case patients was mainly related to the significantly decreased absolute counts of $\mathrm{T}$ cells, including CD4+ and CD8+T cells, similar to the absolute counts of $\mathrm{B}$ cells and natural killer cells but not

\section{ROC Curve}

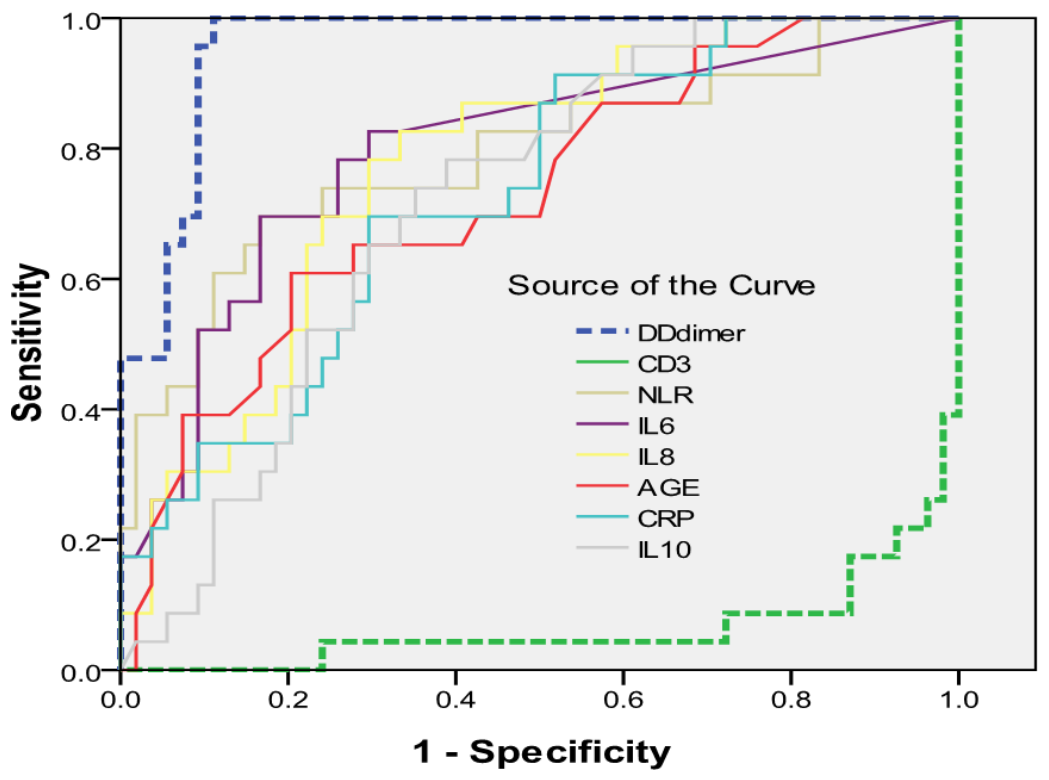

Figure 3. Receiver operating curve analysis used to identify patients with severe or non-severe cases of COVID-2019. 
Table 4. The OR in each of the NLR, IL-6, IL-8, age, D-D dimer and double D-D dimer.

\begin{tabular}{lccccc}
\hline & OR & $\mathbf{9 5 \%}$ CI & & OR & 95\% CI \\
\hline IL-6 & 6.625 & $2.398-18.304$ & D-D >0.5 & 2.75 & $1.999-3.784$ \\
IL-8 & 6.881 & $2.453-19.298$ & D-D $>1$ & 3.733 & $2.241-5.756$ \\
AGE & 4 & $1.493-10.714$ & D-D >2 & 16.5 & $6.832-42.656$ \\
D-D & 16.5 & $6.382-42.656$ & D-D >4 & 29.4 & $7.148-120.9$ \\
NLR & 4.6 & $1.242-17.08$ & D-D >8 & 55 & $6.523-463.7$ \\
\hline
\end{tabular}

to the proportion of LYMs. Interestingly, the ratio of CD4+ to CD8+ was mostly normal. This result is opposite that for acquired immunodeficiency syndrome. In addition, the immunoglobulin levels were normal, which may be explained by the acute infection caused by COVID-19 and half-life of immunoglobulin [20]. The number of $\mathrm{T}$ cells increased three to five days earlier than the relief of clinical symptoms. Thus, this course is associated with favorable outcomes among severe COVID-19 patients.
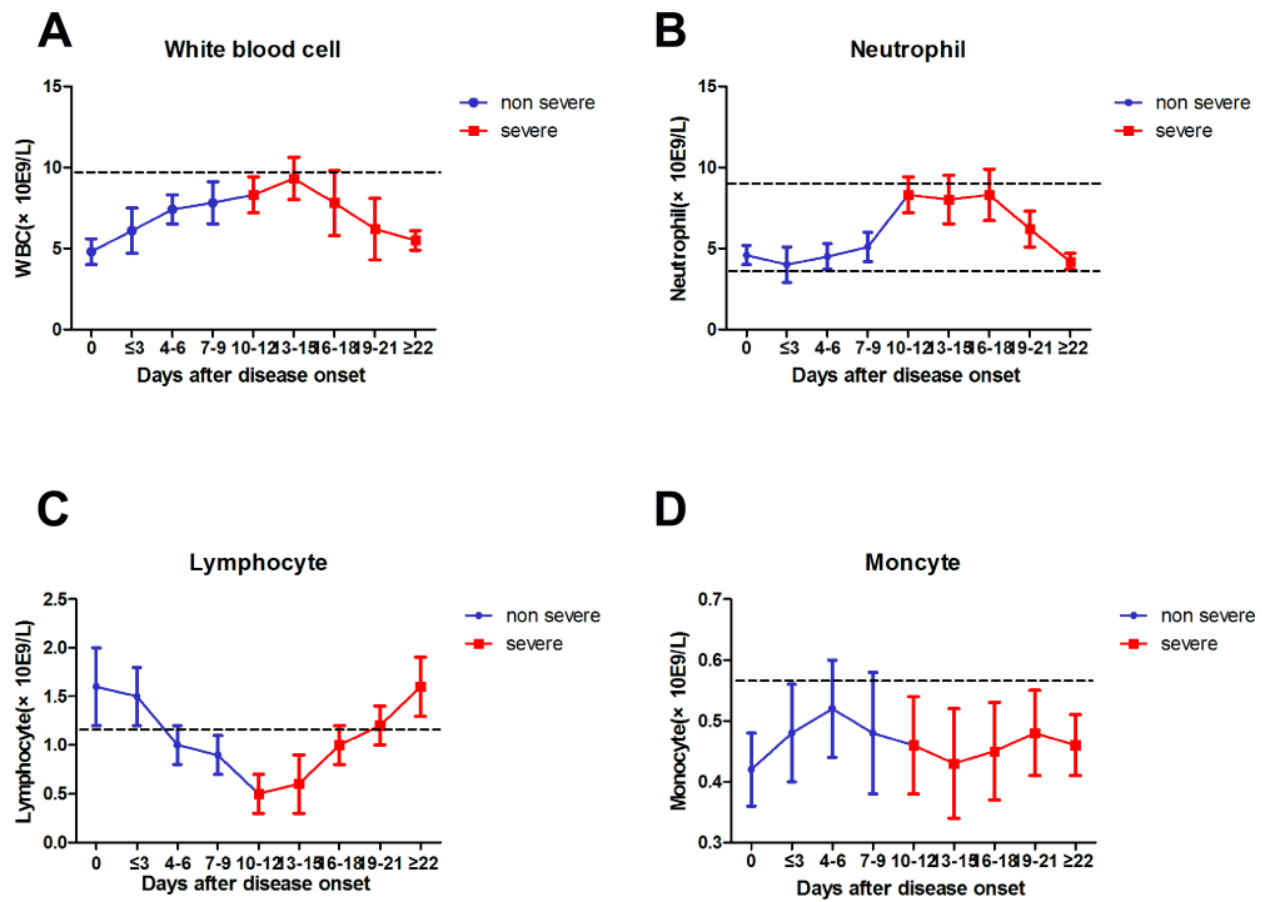

D

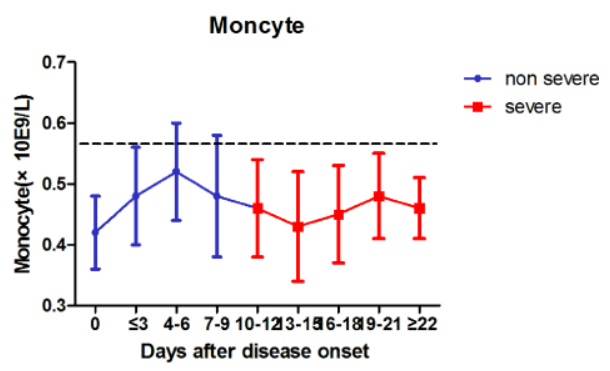

E

$\mathbf{F}$
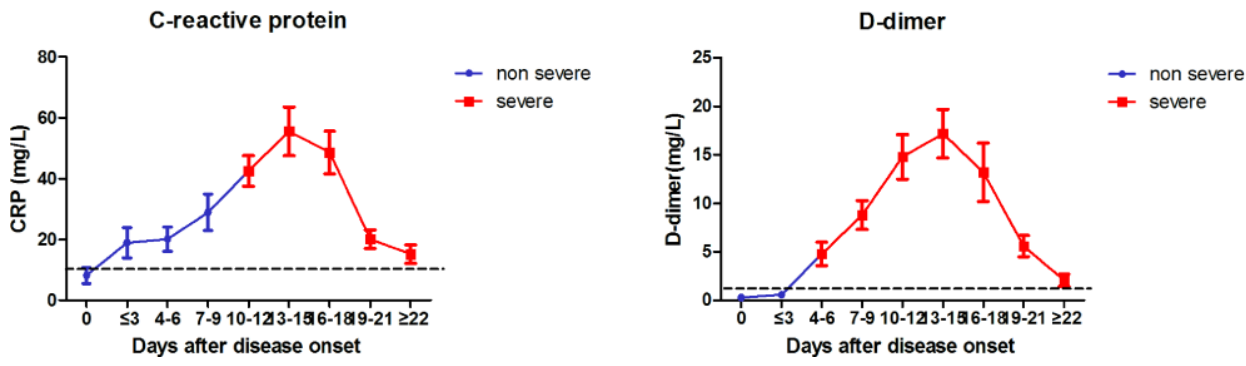

Figure 4. Dynamic results of WBC, NEU, LYM, MON, CRP, D-D dimer from non-severe to severe. 
Elevated levels of proinflammatory cytokines, such as IFN, TNF- $\alpha$, IL-6, and IL-8, are associated with severe lung injury and adverse outcome of SARS-CoV or MERS-CoV infection [20, 21]. Our results also demonstrated that severe COVID-19 patients had higher concentrations of IL-6, IL-8, IL-2,TNF- $\alpha$, and IFN- $\gamma$ in the serum than mild case patients, which suggested that the magnitude of cytokine storm was associated with the disease severity. The results indicated that COVID-19 may act on immune cells, especially T LYMs. T LYM damage is an important factor that causes patient deterioration. Additionally, $\mathrm{T}$ cells are important for dampening overactive innate immune responses during viral infection [22, 23]. Thus, the loss of $T$ cells during COVID-19 may result in aggravated inflammatory responses, whereas restoration of $\mathrm{T}$ cell numbers may alleviate them. The courses of restoration of $\mathrm{T}$ cell numbers are associated with the decreases in serum IL-6, IL-10, IL-2, IL-4, TNF- $\alpha$, and IFN-levels [24]. Therefore, the steady raise in the number of immune cells and the sustained decline in the levels of inflammatory factors are important laboratory manifestations for the clinical improvement of severe patients with COVID-19.

The decreased levels of immune cells and the increased number of inflammatory cells are important manifestations of COVID-19 infection. In the present study, the results supported the hypothesis which indicated that D-D dimer and elevated NLR are independent prognostic biomarkers affecting pneumonia progression in COVID-19 patients [25]. In addition, the integration of elevated NLR to prognostic nomograms may lead to improved prediction. The findings were consistent with those of previous studies on the relationship between NLR and prognosis of other infectious diseases [26]. The following reasons may account for the findings. On the one hand, NEU is a major component of leukocyte population that activates and migrates from the venous system to the immune organ or system. In addition, NEUs interact with distinct cell populations and produce numerous cytokines and effector molecules, such as circulating vascular endothelial growth factor. Furthermore, NEUs can be triggered by virus-related inflammatory factors, such as IL-6, IL- 8 , TNF- $\alpha$, and granulocyte colony stimulating factor, and interferon gamma factors, which are produced by LYM and endothelial cells [27]. On the other hand, the increase in D-D is common in secondary hyperfibrinolysis conditions, such as hypercoagulable state, DIC, sepsis, and kidney disease [23, 28]. Hypercoagulable state blocks immune cell migration to infected organs and is incompatible with the novel coronavirus. Findings showed that the blocking factor is important given the doubled increase of D-D and the seven-fold increased risk ratio. Thus, infection-triggered inflammation increases NLR. Elevated NLR promotes
COVID-19. The clinical symptoms become increasingly severe, and the progress from admission to intensive care unit, cure and discharge, or mechanical ventilation occurs rapidly. Thus, early identification of risk factors for severe COVID-19 patients may facilitate appropriate supportive care and prompt access to the intensive care unit if necessary.

In this study, the laboratory findings of acute renal function injury (4.94 \pm 1.69$)$ appeared earlier than abnormal liver $(7.81 \pm 1.86)$ and heart functions (6.19 \pm 1.83$)$. However, several patients presented the opposite results. Further checking of electronic medical records revealed that these patients had hepatitis B infection and other common diseases, such as liver fibrosis, cyst, fatty liver, and cirrhosis. The causes are still unclear. Except for acute respiratory distress syndrome in patients caused by COVID-19, acute renal dysfunction may occur earlier than other organ dysfunctions, such as those of the liver and heart; these organs need to be monitored by clinicians. Hepatitis B infection is common in China [3, 29]; excluding this factor, whether we can arrive at the same conclusion remains to be further studied. Finally, PCA was performed to identify correlated variables for distinguishing severe and mild case patients (Figure 2). Five of the most contributing variables, namely, D-D dimer, IL-6, IL-8, age, and NLR, were selected as potential prognostic factors for further detailed statistical analysis. The optimal threshold of 3.3 for NLR indicated the superior prognostic possibility of clinical symptoms to change from light to heavy. D-D dimer had the highest sensitivity and specificity and the largest AUC.

Several notable limitations have been observed in this paper. First, the data were obtained from a single clinical research center. Second, the experimental data were limited to Han population of China. Furthermore, the conclusions of this study may differ from those of other scholars at home and abroad and must be further improved in clinical cases. Finally, accurate clinical data were lacking for the small number of patients with mild illness because of time constraints.

In conclusion, the study revealed that LYM subsets and cytokine profiles in the peripheral blood of COVID-19 patients were longitudinally characterized. D-D dimer increased from 0.5 to 8 , and the risk ratio increased from 2.75 to 55 , eventually leading to DIC. Acute renal function damage occurred earlier than the abnormal heart and liver functions. Finally, the kinetics features of immune parameters associated with the disease severity were determined, and D-D dimer and NLR were identified as the most useful prognostic factors for predicting severe COVID-19 cases. 


\section{MATERIALS AND METHODS}

\section{Patients}

We performed a retrospective study on the clinical characteristics, epidemiological, demographic, laboratory data, and outcome data of laboratoryconfirmed cases with 2019-nCoV. Cases were diagnosed based on the WHO interim guidance [5]; non-severe patients met all the following conditions: (1) epidemiological history, (2) fever or other respiratory symptoms, (3) typical computed tomography image of abnormities of viral pneumonia, and (4) positive result in reverse transcription polymerase chain reaction (RT-PCR) for SARS-CoV-2 RNA. Severe patients additionally met at least one of the following conditions: (1) shortness of breath, RR $\geq 30$ times/min, (2) oxygen saturation (resting state) $\leq 93 \%$, (3) $\mathrm{PaO}_{2} / \mathrm{FiO}_{2} \leq 300$ $\mathrm{mmHg}$. Infections with other respiratory viruses, including influenza A virus, influenza B virus, respiratory syncytial virus and parainfluenza virus were excluded by serological test. Informed consent was waived in light of the anonymous, retrospective, and observational character of this study

\section{Clinical characteristics and laboratory data}

The epidemiological characteristics (including recent exposure history), clinical symptoms and signs, and laboratory findings were extracted from electronic medical records. Laboratory assessments consisted of complete blood count, blood chemistry, coagulation test, liver and renal function, C-reactive protein (CRP), LYM subsets, and cytokines. The severity of COVID19 was defined in accordance with the international guidelines for community-acquired pneumonia. The LYM test kit (FC 500 MCL, BECKMAN, USA) was used for LYM subset analysis (CD3+, CD3+CD4+, CD3+CD8+, CD16+CD56+, and CD3-CD19+). Plasma cytokines (interleukin (IL)-5, interferon (IFN)- $\alpha$, IL-2, IL-6, IL-1 $\beta$, IL-10, IFN- $\gamma$, IL-8, IL-17, IL-4, and IL12P70) were detected with human Th1/2 cytokine kit II (ACEA NovoCyte, Guangzhou, China). All tests were performed in accordance with the product manual.

\section{Statistical analysis}

Continuous variables were expressed as means and standard deviations or medians and interquartile ranges as appropriate. Categorical variables were summarized as the counts and percentages in each category. Wilcoxon ranksum tests were applied to continuous variables. Chi-square tests and Fisher's exact tests were used for categorical variables as appropriate. Optimal cutoff values of the continuous neutrophil (NEU)-to-LYM ratio (NLR), Age, D-D, IL-2, IL-6, IL-8, and CRP were calculated by applying the receiver operating curve analysis (ROC). Hazard risk and $95 \%$ confidence interval were used as common measures to assess relative risk. Principal component analysis (PCA) was performed to identify the major contributing factors among clinical parameters to distinguish mild and severe cases of COVID-19 patients. $\mathrm{P}<0.05$ was recognized as statistically significant. All statistical calculations were performed using SPSS 17.0 software (SPSS Inc, Chicago, USA).

\section{AUTHOR CONTRIBUTIONS}

Jian-ping Liu: Designed the study. Min Wang: Data curation. Ai-ping Yang: Methodology, software, writing - original draft preparation. Hui-ming Li: Collected the samples, detected serum marker levels. Wen-qiang Tao: Writing-reviewing. Xue-jing Yang and Wen-juan Yang: Editing. All authors read and approved the final manuscript.

\section{ACKNOWLEDGMENTS}

We thank all the doctors, nurses, disease control workers, and researchers who have fought bravely and ceaseless against the virus on the frontline during the COVID-19 epidemic, some of whom lost their lives in doing so.

\section{CONFLICTS OF INTEREST}

The authors declared that they have no conflicts of interest.

\section{FUNDING}

This work is supported by Hangzhou Science and Technology Bureau(20181228Y86).

\section{REFERENCES}

1. Li Q, Guan X, Wu P, Wang X, Zhou L, Tong $Y$, Ren R, Leung KSM, Lau EHY, Wong JY, Xing $X$, Xiang N, Wu Y, et al. Early transmission dynamics in Wuhan, China, of novel coronavirus-infected pneumonia. N Engl J Med. 2020; 382:1199-1207. https://doi.org/10.1056/NEJMoa2001316 PMID:31995857

2. Lu H, Stratton CW, Tang YW. Outbreak of pneumonia of unknown etiology in Wuhan, China: The mystery and the miracle. J Med Virol. 2020; 92:401-02. https://doi.org/10.1002/jmv.25678 PMID: $\underline{31950516}$

3. Hui DS, Azhar El, Madani TA, Ntoumi F, Kock R, Dar O, Ippolito G, Mchugh TD, Memish ZA, Drosten C, Zumla A, Petersen E. The continuing 2019-nCoV epidemic 
threat of novel coronaviruses to global health - The latest 2019 novel coronavirus outbreak in Wuhan, China. Int J Infect Dis. 2020; 91:264-66.

https://doi.org/10.1016/j.ijid.2020.01.009

PMID:31953166

4. Huang $C$, Wang $Y$, Li X, Ren L, Zhao J, Hu Y, Zhang L, Fan G, Xu J, Gu X, Cheng Z, Yu T, Xia J, et al. Clinical features of patients infected with 2019 novel coronavirus in Wuhan, China. Lancet. 2020; 395:497-506. https://doi.org/10.1016/S0140-6736(20)30183-5 PMID:31986264

5. WHO. Clinical management of severe acute respiratory infection when novel coronavirus (2019-nCoV) infection is suspected: interim guidance. Jan 11, 2020. https://apps.who.int/iris/handle/10665/330854

6. WHO. Clinical management of severe acute respiratory infection when novel coronavirus (2019-nCoV) infection is suspected: interim guidance, Jan 20, 2020. https://apps.who.int/iris/handle/10665/330893

7. Yin $Y$, Wunderink RG. MERS, SARS and other coronaviruses as causes of pneumonia. Respirology. 2018; 23:130-37.

https://doi.org/10.1111/resp.13196 PMID:29052924

8. Chan JF, Yuan S, Kok KH, To KK, Chu H, Yang J, Xing F, Liu J, Yip CC, Poon RW, Tsoi HW, Lo SK, Chan KH, et al. A familial cluster of pneumonia associated with the 2019 novel coronavirus indicating person-to-person transmission: a study of a family cluster. Lancet. 2020; 395:514-23.

https://doi.org/10.1016/S0140-6736(20)30154-9 PMID:31986261

9. Wang D, Hu B, Hu C, Zhu F, Liu X, Zhang J, Wang B, Xiang $\mathrm{H}$, Cheng $\mathrm{Z}$, Xiong $\mathrm{Y}$, Zhao $\mathrm{Y}$, Li $\mathrm{Y}$, Wang $\mathrm{X}$, Peng $\mathrm{Z}$. Clinical characteristics of 138 hospitalized patients with 2019 novel coronavirus-infected pneumonia in Wuhan, China. JAMA. 2020. [Epub ahead of print]. JAMA

. 2020 Feb 7;323(11):1061-1069 https://doi.org/10.1001/jama.2020.1585 PMID:32031570

10. Chen N, Zhou M, Dong X, Qu J, Gong F, Han Y, Qiu Y, Wang J, Liu Y, Wei Y, Xia J, Yu T, Zhang X, Zhang L. Epidemiological and clinical characteristics of 99 cases of 2019 novel coronavirus pneumonia in Wuhan, China: a descriptive study. Lancet. 2020; 395:507-13. https://doi.org/10.1016/S0140-6736(20)30211-7 PMID:32007143

11. Chang $D$, Lin $M$, Wei L, Xie L, Zhu G, Dela Cruz CS, Sharma L. Epidemiologic and clinical characteristics of novel coronavirus infections involving 13 patients outside Wuhan, China. JAMA. 2020; 323:1092-1093. https://doi.org/10.1001/jama.2020.1623 PMID:32031568
12. Liu J, Zheng X, Tong Q, Li W, Wang B, Sutter K, Trilling M, Lu M, Dittmer U, Yang D. Overlapping and discrete aspects of the pathology and pathogenesis of the emerging human pathogenic coronaviruses SARSCoV, MERS-CoV, and 2019-nCoV. J Med Virol. 2020; 92:491-94.

https://doi.org/10.1002/jmv.25709 PMID:32056249

13. Zhu N, Zhang D, Wang $W$, Li X, Yang B, Song J, Zhao X, Huang B, Shi W, Lu R, Niu P, Zhan F, Ma X, et al, and China Novel Coronavirus Investigating and Research Team. A novel coronavirus from patients with pneumonia in China, 2019. N Engl J Med. 2020; 382:727-33.

https://doi.org/10.1056/NEJMoa2001017 PMID:31978945

14. Xiang N, Havers F, Chen T, Song Y, Tu W, Li L, Cao Y, Liu B, Zhou L, Meng L, Hong Z, Wang R, Niu Y, et al. Use of national pneumonia surveillance to describe influenza A(H7N9) virus epidemiology, China, 2004-2013. Emerg Infect Dis. 2013; 19:1784-90.

https://doi.org/10.3201/eid1911.130865 PMID:24206646

15. Ying $\mathrm{HQ}$, Deng $\mathrm{QW}$, He BS, Pan $\mathrm{YQ}$, Wang $F$, Sun $\mathrm{HL}$, Chen J, Liu X, Wang SK. The prognostic value of preoperative NLR, d-NLR, PLR and LMR for predicting clinical outcome in surgical colorectal cancer patients. Med Oncol. 2014; 31:305.

https://doi.org/10.1007/s12032-014-0305-0 PMID:25355641

16. Wang FS, Zhang $\mathrm{C}$. What to do next to control the 2019-nCoV epidemic? Lancet. 2020; 395:391-93. https://doi.org/10.1016/S0140-6736(20)30300-7 PMID:32035533

17. Song HD, Tu CC, Zhang GW, Wang SY, Zheng K, Lei LC, Chen QX, Gao YW, Zhou HQ, Xiang $\mathrm{H}$, Zheng HJ, Chern SW, Cheng F, et al. Cross-host evolution of severe acute respiratory syndrome coronavirus in palm civet and human. Proc Natl Acad Sci USA. 2005; 102:2430-35.

https://doi.org/10.1073/pnas.0409608102 PMID:15695582

18. Haagmans BL, Al Dhahiry SH, Reusken CB, Raj VS, Galiano M, Myers R, Godeke GJ, Jonges M, Farag E, Diab A, Ghobashy H, Alhajri F, Al-Thani M, et al. Middle East respiratory syndrome coronavirus in dromedary camels: an outbreak investigation. Lancet Infect Dis. 2014; 14:140-45.

https://doi.org/10.1016/S1473-3099(13)70690-X PMID:24355866

19. Tao Y, Shi M, Chommanard C, Queen K, Zhang J, Markotter W, Kuzmin IV, Holmes EC, Tong S. Surveillance of bat coronaviruses in Kenya identifies relatives of human coronaviruses NL63 and 229E and 
their recombination history. J Virol. 2017; 91: e01953-16.

https://doi.org/10.1128/JVI.01953-16

PMID:28077633

20. Liu J, Li S, Liu J, Liang B, Wang X, Wang H, Li W, Tong Q, Yi J, Zhao L, Xiong L, Guo C, Tian J, et al. Longitudinal characteristics of lymphocyte responses and cytokine profiles in the peripheral blood of SARS-CoV-2 infected patients. EBioMedicine. 2020; 55:102763. https://doi.org/10.1016/j.ebiom.2020.102763 PMID:32361250

21. Hanrahan V, Currie MJ, Gunningham SP, Morrin HR, Scott PA, Robinson BA, Fox SB. The angiogenic switch for vascular endothelial growth factor (VEGF)-A, VEGF$B$, VEGF-C, and VEGF-D in the adenoma-carcinoma sequence during colorectal cancer progression. J Pathol. 2003; 200:183-94.

https://doi.org/10.1002/path.1339

PMID:12754739

22. Kim SL, Lee ST, Trang KT, Kim SH, Kim IH, Lee SO, Kim DG, Kim SW. Parthenolide exerts inhibitory effects on angiogenesis through the downregulation of VEGF/VEGFRs in colorectal cancer. Int J Mol Med. 2014; 33:1261-67.

https://doi.org/10.3892/ijmm.2014.1669

PMID:24573421

23. Kuper H, Adami HO, Trichopoulos D. Infections as a major preventable cause of human cancer. J Intern Med. 2000; 248:171-83.

https://doi.org/10.1046/i.1365-2796.2000.00742.x PMID:10971784

24. Blaser MJ, Chyou PH, Nomura A. Age at establishment of Helicobacter pylori infection and gastric carcinoma, gastric ulcer, and duodenal ulcer risk. Cancer Res. 1995; 55:562-65.

PMID:7834625
25. Yang AP, Liu JP, Tao WQ, Li HM. The diagnostic and predictive role of NLR, d-NLR and PLR in COVID-19 patients. Int Immunopharmacol. 2020; 84:106504.

https://doi.org/10.1016/j.intimp.2020.106504

PMID:32304994

26. Scholl SM, Pallud C, Beuvon F, Hacene K, Stanley ER, Rohrschneider L, Tang R, Pouillart P, Lidereau R. Anticolony-stimulating factor-1 antibody staining in primary breast adenocarcinomas correlates with marked inflammatory cell infiltrates and prognosis. J Natl Cancer Inst. 1994; 86:120-26.

https://doi.org/10.1093/jnci/86.2.120

PMID: 8271294

27. Shacter E, Weitzman SA. Chronic inflammation and cancer. Oncology (Williston Park). 2002; 16:217-26. PMID: 11866137

28. Rabinowich $\mathrm{H}$, Cohen $\mathrm{R}$, Bruderman I, Steiner $\mathrm{Z}$, Klajman A. Functional analysis of mononuclear cells infiltrating into tumors: lysis of autologous human tumor cells by cultured infiltrating lymphocytes. Cancer Res. 1987; 47:173-77.

PMID: $\underline{3491673}$

29. Menges T, Engel J, Welters I, Wagner RM, Little S, Ruwoldt R, Wollbrueck M, Hempelmann G. Changes in blood lymphocyte populations after multiple trauma: association with posttraumatic complications. Crit Care Med. 1999; 27:733-40. https://doi.org/10.1097/00003246-199904000-00026 PMID:10321662 